\title{
Enhancing Diagnostic Accuracy of aMCI in the Elderly: Combination of Olfactory Test, Pupillary Response Test, BDNF Plasma Level, and APOE Genotype
}

\author{
Yuda Turana, ${ }^{1}$ Teguh Asaat S. Ranakusuma, ${ }^{2}$ Jan Sudir Purba, ${ }^{2}$ \\ Nurmiati Amir, ${ }^{3}$ Siti Airiza Ahmad, ${ }^{2}$ Moh. Hasan Machfoed, ${ }^{4}$ Yvonne Suzy Handayani, ${ }^{5}$ \\ Asmarinah, ${ }^{6}$ and Sarwono Waspadji ${ }^{7}$ \\ ${ }^{1}$ Department of Neurology, Faculty of Medicine, Atma Jaya Catholic University of Indonesia, Jl. Pluit Raya No. 2, \\ North Jakarta 14440, Indonesia \\ ${ }^{2}$ Department of Neurology, Faculty of Medicine, University of Indonesia, Jl. Salemba Raya No. 6, Central Jakarta 10430, Indonesia \\ ${ }^{3}$ Department of Psychiatry, Faculty of Medicine, University of Indonesia, Jl. Salemba Raya No. 6, Central Jakarta 10430, Indonesia \\ ${ }^{4}$ Department of Neurology, Faculty of Medicine, University of Airlangga, Kampus A, Jl. Mayjen. Prof. Dr. Moestopo No. 47, \\ Surabaya 60131, Indonesia \\ ${ }^{5}$ Center of Health Research, Atma Jaya Catholic University of Indonesia, Jl. Pluit Raya No. 2, North Jakarta 14440, Indonesia \\ ${ }^{6}$ Department of Biology, Faculty of Medicine, University of Indonesia, Jl. Salemba Raya No. 6, Central Jakarta 10430, Indonesia \\ ${ }^{7}$ Department of Internal Medicine, Faculty of Medicine, University of Indonesia, Jl. Salemba Raya No. 6, \\ Central Jakarta 10430, Indonesia
}

Correspondence should be addressed to Yuda Turana; yudaturana@yahoo.com

Received 28 June 2013; Revised 2 December 2013; Accepted 16 December 2013; Published 2 February 2014

Academic Editor: Francesco Panza

Copyright (C) 2014 Yuda Turana et al. This is an open access article distributed under the Creative Commons Attribution License, which permits unrestricted use, distribution, and reproduction in any medium, provided the original work is properly cited.

\begin{abstract}
Background. Amnestic Mild Cognitive Impairment (aMCI) often progresses to Alzheimer's disease. There are clinical markers and biomarkers to identify the degenerative process in the brain. Objectives. To obtain the diagnostic values of olfactory test, pupillary response to tropicamide $0.01 \%$, BDNF plasma level, and APOE $\varepsilon 4$ in diagnosing aMCI. Methods. Cross-sectional, comparative analysis. Results. There were 109 subjects enrolled (aMCI: 51, normal cognition: 58) with age $64 \pm 5.54$ years. For diagnosing aMCI, cut-off point for the olfactory score was $<7$ out of 10 and $>22 \%$ for pupil dilatation response. Low BDNF plasma level was related significantly with olfactory deficits and aMCI $(P<0.05)$. Four of five subjects with homozygote e4 presented with multiple-domain aMCI. This group displayed the lowest means of olfactory score and the highest means of pupillary hypersensitivity response $(P<$ 0.0001). Combination of olfactory deficit and pupillary hypersensitivity response in detection of aMCI was beneficial with $\mathrm{Sp}$ 91\% and PPV 87\%. In conjunction with clinical markers, BDNF plasma level and presence of APOE e4+ improved Sp and PPV. Conclusions. Combination of olfactory test and pupillary response test was useful as diagnostic tool in aMCI. In conjunction with clinical markers, low level of BDNF plasma and presence of APOE e4 improved the diagnostic value.
\end{abstract}

\section{Introduction}

Mild Cognitive Impairment (MCI) is a transitional state between normal cognitive function and dementia. It is predicted that $50-80 \%$ of patients with MCI will eventually develop dementia in the later stage of the disease [1]. The memory-predominant subtype, amnestic MCI (aMCI) conveys the highest risk of progressing to Alzheimer's dementia
(AD) [2]. Neuropathologic study also has shown that aMCI seemed to be intermediate between the neurofibrillary changes of aging and the pathologic features of very early AD [3]. Dementia and MCI are clinical diagnosis based on psychometric evaluation. In spite of this evaluation being the gold standard, there are still limitations to its usage (e.g, illiterate patients, visual and hearing problems, and pseudoamnesia). There are clinical and biologic markers available 
to identify the degenerative process in the brain that have been studied, such as olfactory test [4-16], pupil dilatation response to tropicamide [17-26], APOE genotype [27-34], and brain derived neurotrophic factor (BDNF) plasma level [35-42].

Previous report has featured relationship between several markers with degenerative process and dementia such as olfactory deficits that is now being used as practice parameter in diagnosis of Parkinson disease [43]. Other studies published the presence of olfactory deficit in AD patients [1316]. Studies performed in aMCI patients also revealed that patients with low olfactory scores were more likely to progress toward dementia [11].

Pupillary hypersensitivity response to tropicamide in dementia patients has been recorded in many studies. Scinto et al. reported a cut-off point of $13 \%$ in 30 minutes to differentiate dementia and normal cognition in the elderly using $0.01 \%$ tropicamide [17]. Another study published by Iijima et al. using $0.005 \%$ tropicamide showed hypersensitivity in pupil dilatation response in $\mathrm{AD}$ patients when compared with non-AD subjects [20].

Based on the former reports, olfactory test and pupil dilatation response to tropicamide could be the new potential markers in detecting aMCI. To our knowledge, there has not been a study combining the two factors for diagnostic purpose in aMCI patients. We are also aware of APOE and BDNF as markers of the degenerative process in the brain. Therefore, we want to investigate whether combination of olfactory test and pupillary response to tropicamide $0.01 \%$ has diagnosis value and whether presence of APOE $\varepsilon 4$ and low BDNF plasma level can be useful to enhance diagnostic accuracy of aMCI.

\section{Methods}

This is a cross-sectional study, comparative analysis in elderly with normal cognition and those presenting with aMCI. The study consisted of all subjects participating in the baseline cognitive assessment of study on quality of life in elderly in Kali Anyar, West Jakarta, done by Center of Health Research Atma Jaya Catholic University of Indonesia, about 12 months prior to this study (between August 2011 and September 2011). Inclusion criteria are age $\geq 60$ years old and being literate (reading and writing skills). Exclusion criteria are hearing problems, major psychiatric disorders, depression (Geriatric Depression Scale/GDS >4) [44, 45], history of cataract surgery, severe medical illness, past consumption of drugs affecting brain's function and structure, history of cerebrovascular disease, epilepsy, and diabetes mellitus (consumption of antiglycaemic drugs or fasting blood glucose $\geq 126 \mathrm{mg}$ / dL) $[46,47]$.

Cognitive assessments were conducted and the results were compared with baseline data. Assessments were done using Forward Digit Span, Clock Drawing Test and MMSE, Verbal Fluency (VF), Boston Naming Test (BNT), Word List Memory Immediate Recall (WLM IR), World List Memory Delayed Recall (WLM DR), Recognition, and Constructional
Praxis (CP) from CERAD (Consortium to Establish a Registry for Alzheimer's Disease) Neuropsychological Battery [48].

Diagnosis of MCI was based according to Consortium Criteria proposed by the International Working Group on MCI [49]. The criteria include (1) absence of dementia according to DSM IV or ICD-10, (2) evidence of cognitive decline overtime on objective cognitive task, and (3) preserved baseline activities of daily living or only minimal impairment in complex instrumental functions. Definition of cognitive decline is decrease $\geq 2$ points/year in one cognitive instrument (MMSE/WLM IR/WLM DR) or decrease $\geq 1$ point/year in at least 2 cognitive instruments (MMSE/WLM IR/WLM DR). Single-domain aMCI was diagnosed if subjects are showing deficit in memory task (Saving Score $<65 \%$ or WLM IR (third repetition) $<8$ ), but not in any other area of cognitive domains. Multiple-domain aMCI was diagnosed if there was presence of memory deficit and also in other cognitive domains. Nonamnestic MCI (naMCI) was diagnosed if there was impairment in cognitive domains other than memory (we excluded naMCI in this study). The regional ethical committee approved the study and written informed consent was obtained from each individual.

2.1. Apolipoprotein E and BDNF Plasma Level. Blood samples $(10 \mathrm{~mL})$ were collected from each subject. Routine blood test was performed along with fasting blood glucose, lipid profile, APOE, and BDNF plasma level. APOE and BDNF were done blinded for all clinical data. APOE measurement was completed using Restriction Fragment Length Polymorphism (RFLP) method. In this study, we used High Pure Polymerase Chain Reaction (PCR) Template Preparation Kit for extraction and PCR was performed using FastStart Taq DNA Polymerase (Roche Applied Biosystem). BDNF was measured using ELISA kit from R\&D Systems.

2.2. Olfactory Test. Examination of olfactory nerve function was performed using 10 odors commonly found in Indonesia: cajuput oil, coffee, jasmine, menthol, tobacco, kerosene, pandan, camphor, chocolate, and orange [50]. The odors were preserved in similar containers, sealed, and coded continuously. Subjects were allowed to smell the odors twice for $5 \mathrm{sec}$ onds before being asked to identify them. They were given a $30 \mathrm{sec}$ break prior to identifying the next odor.

\subsection{Pupillary Response to $0.01 \%$ Tropicamide. The examiner} instilled a drop of $0.01 \%$ tropicamide on one subject's eye, while the other eye received saline as control. We measured pupil diameter at 30 minutes, 40 minutes, and 50 minutes [17] using Colvard pupillometry in a semidarkened room [51, 52]. Pupillary response was examined using Granholm et al. method by measuring anisocoria (percent difference between tropicamide and saline eyes at each time point). This method was preferred to reduce bias resulting from fatigue, stress, drugs, and others that might influence the pupil size [53].

2.4. Statistical Analysis. Differences in proportions were assessed by means of chi-square, Mann-Whitney tests, or 


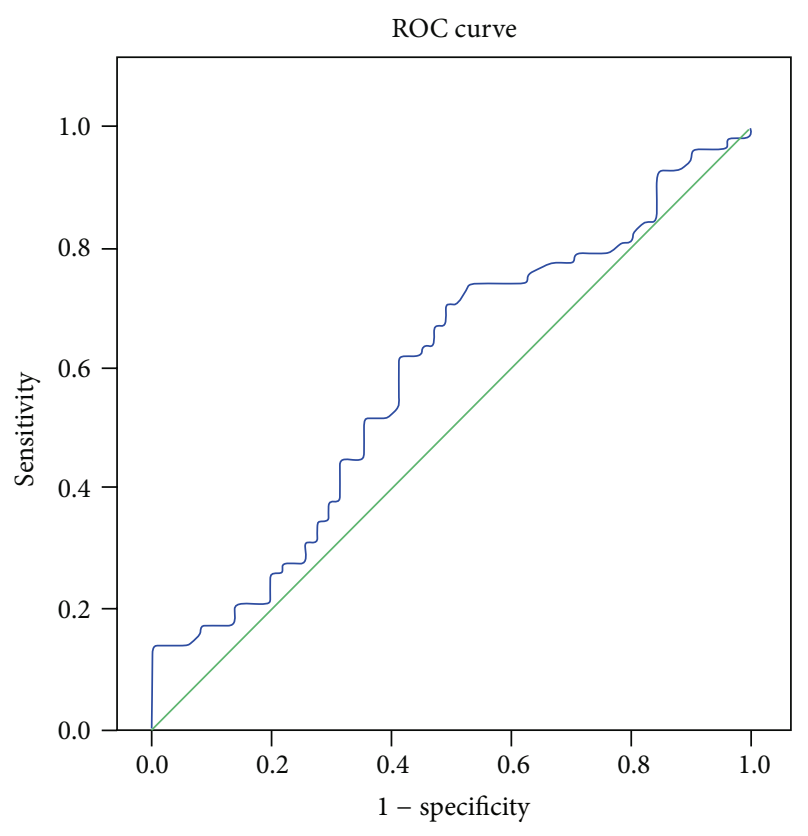

FIGURE 1: The ROC curve of BDNF plasma level and aMCI.

Kruskall-Wallis tests. The tests were performed to compare the demographic and clinical factors between subjects with aMCI and cognitively normal individuals in both groups. Any significant items were then entered into a multivariate logistic regression to develop a model for predicting aMCI, using stepwise selection with an inclusion criteria of $P<0.05$. Statistical analysis was performed using the SPSS 15.0 software (SPSS Inc., Chicago, IL, USA). The level of significance was set at $P<0.05$ for all statistical analyses.

\section{Results}

There were 109 subjects enrolled in this study (normal cognition: 58, single-domain aMCI: 10 , and multiple-domain aMCI: 41); 77 subjects were women $(70.6 \%)$ and most of the subjects had $<6$ years of formal education (40\%) (Table 1). Using ROC curve, we calculated the cut-off points to determine aMCI as follows: cut-off point for low BDNF plasma level $\leq 1314 \mathrm{pg} / \mathrm{mL}$, less than 7 for olfactory deficit, and pupillary hypersensitivity response $>22 \%$ (maximal peak diameter on 30 minutes) (Figures 1, 2, and 3).

The majority of subjects had multiple-domain aMCI (35\%). There was no significant relationship between aMCI and APOE $\varepsilon 4$ genotype. However, four of five subjects with $\varepsilon 4$ homozygote also showed multiple-domain aMCI. Group with multiple-domain aMCI had the lowest means of olfactory score and the highest means of pupillary hypersensitivity response $(P<0.0001)$ (Table 2$)$.

After performing chi-square test, we identified three variables with $P<0.05$ : pupillary response to tropicamide, olfactory nerve deficit, and BDNF plasma level (Table 1). We further analyzed using logistic regression test and found significant relationship between pupillary hypersensitivity

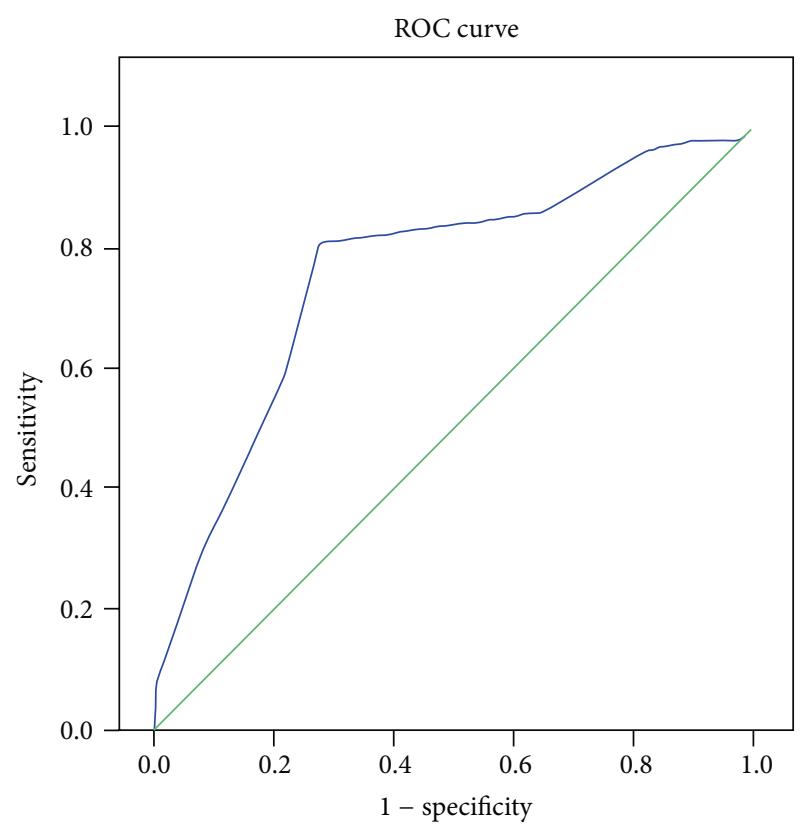

FIgURE 2: The ROC curve of olfactory deficit and aMCI.

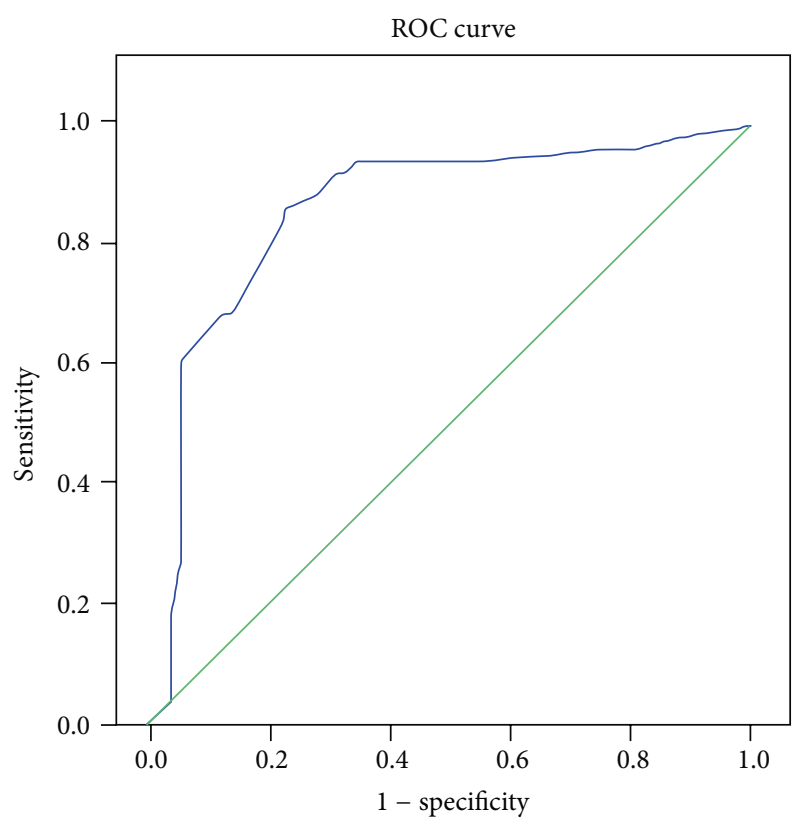

FIgURE 3: The ROC curve of pupillary response and aMCI.

response $(\mathrm{OR}=13.69)$ and olfactory nerve deficit $(\mathrm{OR}=5.99)$ with aMCI.

There was no significant relationship between $\varepsilon 4$ genotype with olfactory scores and pupillary response $(P>0.05)$. However, we observed that subjects with $\varepsilon 4 / \varepsilon 4$ genotypes scored the lowest in olfactory test and had the highest pupillary response. There was also significant relationship between low BDNF plasma level with lower olfactory scores $(P=0.012)$. 
TABLE 1: Demographic and clinical status in elderly with aMCI and normal cognition.

\begin{tabular}{|c|c|c|c|c|c|}
\hline Variable & $\mathrm{aMCI}$ & Normal & $P$ & Odds ratio & $95 \% \mathrm{CI}$ \\
\hline \multicolumn{6}{|l|}{ Age (years) } \\
\hline (a) $\leq 65$ & $36(45.6 \%)$ & $43(54.4 \%)$ & \multirow{2}{*}{0.84} & \multirow{2}{*}{0.84} & \multirow{2}{*}{$0.36-1.94$} \\
\hline (b) $>65$ & $15(50.0 \%)$ & $15(50.0 \%)$ & & & \\
\hline \multicolumn{6}{|l|}{ Gender } \\
\hline (a) Men & $16(50.0 \%)$ & $16(50.0 \%)$ & \multirow{2}{*}{0.82} & \multirow{2}{*}{1.20} & \multirow{2}{*}{$0.53-2.74$} \\
\hline (b) Women & $35(45.5 \%)$ & $42(54.5 \%)$ & & & \\
\hline \multicolumn{6}{|l|}{ Years of education } \\
\hline (a) $<6$ years & $20(45.5 \%)$ & $24(54.5 \%)$ & \multirow{2}{*}{0.97} & \multirow{2}{*}{0.91} & \multirow{2}{*}{$0.42-1.97$} \\
\hline (b) $\geq 6$ years & $31(47.7 \%)$ & $34(52.3 \%)$ & & & \\
\hline \multicolumn{6}{|l|}{ Body mass index (BMI) } \\
\hline (a) Overweight $\left(\geq 25.0 \mathrm{~kg} / \mathrm{m}^{2}\right)$ & $26(48.1 \%)$ & $28(51.9 \%)$ & \multirow{2}{*}{0.93} & \multirow{2}{*}{1.11} & \multirow{2}{*}{$0.53-2.37$} \\
\hline (b) Normal $\left(<25.0 \mathrm{~kg} / \mathrm{m}^{2}\right)$ & $25(45.5 \%)$ & $30(54.5 \%)$ & & & \\
\hline \multicolumn{6}{|l|}{ APOE genotype } \\
\hline (a) $\varepsilon 4+$ & $14(46.7 \%)$ & $16(53.3 \%)$ & \multirow{2}{*}{1.00} & \multirow{2}{*}{1.00} & \multirow{2}{*}{$0.43-2.32$} \\
\hline (b) $\varepsilon 4-$ & $36(46.8 \%)$ & $41(53.2 \%)$ & & & \\
\hline \multicolumn{6}{|l|}{ BDNF level } \\
\hline (a) Low ( $\leq 1314 \mathrm{pg} / \mathrm{mL})$ & $26(60.5 \%)$ & $17(39.5 \%)$ & \multirow{2}{*}{0.04} & \multirow{2}{*}{2.51} & \multirow{2}{*}{$1.14-5.52$} \\
\hline (b) High (>1314 pg/mL) & $25(37.9 \%)$ & $41(62.1 \%)$ & & & \\
\hline \multicolumn{6}{|l|}{ Olfactory deficit } \\
\hline (a) Yes (Skor 0-6) & $37(77.1 \%)$ & $11(22.9 \%)$ & \multirow{2}{*}{$<0.0001$} & \multirow{2}{*}{11.29} & \multirow{2}{*}{$4.59-27.76$} \\
\hline (b) No (Skor 7-10) & $14(23.0 \%)$ & $47(77.0 \%)$ & & & \\
\hline $\begin{array}{l}\text { Pupillary hypersensitivity to } \\
\text { tropicamide }\end{array}$ & & & & & \\
\hline (a) Yes $(>22 \%)$ & $44(77.2 \%)$ & $13(22.8 \%)$ & $<0.0001$ & 21.76 & $7.94-59.65$ \\
\hline (b) No $(\leq 22 \%)$ & $7(13.5 \%)$ & $45(86.5 \%)$ & & & \\
\hline Systolic BP & & & & & \\
\hline (a) Hypertension ( $\geq 140 \mathrm{mmHg}$ ) & $23(44.2 \%)$ & $29(55.8 \%)$ & 0.75 & 0.82 & $0.39-1.75$ \\
\hline (b) Normal (<140 mmHg) & $28(49.1 \%)$ & $29(50.9 \%)$ & & & \\
\hline Diastolic BP & & & & & \\
\hline (a) Hypertension $(\geq 90 \mathrm{mmHg})$ & $29(52.7 \%)$ & $26(47.3 \%)$ & 0.29 & 162 & $076-346$ \\
\hline (b) Normal (<90 mmHg) & $22(40.7 \%)$ & $32(59.3 \%)$ & & & \\
\hline LDL & & & & & \\
\hline (a) High $(\geq 130 \mathrm{mg} / \mathrm{dL})$ & $35(52.2 \%)$ & $32(47.8 \%)$ & 0.21 & 1.78 & $0.81-3.90$ \\
\hline (b) Normal (<130 mg/dL) & $16(38.1 \%)$ & $26(61.9 \%)$ & & & \\
\hline $\mathrm{HDL}$ & & & & & \\
\hline $\begin{array}{l}\text { (a) Low ( }<40 \mathrm{mg} / \mathrm{dL} \text { for men, } \\
<50 \mathrm{mg} / \mathrm{dL} \text { for women) }\end{array}$ & $18(46.2 \%)$ & $21(53.8 \%)$ & 1.00 & 0.96 & $0.44-2.11$ \\
\hline $\begin{array}{l}\text { (b) Normal ( } \geq 40 \mathrm{mg} / \mathrm{dL} \text { for men, } \\
\geq 50 \mathrm{mg} / \mathrm{dL} \text { for women) }\end{array}$ & $33(47.1 \%)$ & $37(52.9 \%)$ & & & \\
\hline
\end{tabular}

TABLE 2: Pupillary response and olfactory score in elderly with aMCI and normal cognition.

\begin{tabular}{lcccr}
\hline Variable & aMCI & & Normal & $P^{*}$ \\
& Single domain & Multiple domain & $17.20 \pm 13.81$ & $<0.0001$ \\
Pupillary response (\%) & $30.4 \pm 9.30$ & $36.06 \pm 15.85$ & $7.53 \pm 1.68$ & $<0.0001$ \\
Olfactory score & $6.10 \pm 1.60$ & $5.80 \pm 1.89$ & & \\
\hline
\end{tabular}

\footnotetext{
${ }^{*}$ Kruskal-Wallis test.
} 
TABLE 3: Combination of olfactory deficit, pupillary hypersensitivity response, APOE $\varepsilon 4$, and BDNF plasma level in elderly with aMCI and normal cognition.

\begin{tabular}{|c|c|c|c|c|c|c|c|c|}
\hline & $\mathrm{aMCI}$ & Normal & $\begin{array}{l}\text { Sv } \\
(\%)\end{array}$ & $\begin{array}{l}\mathrm{Sp} \\
(\%)\end{array}$ & $\begin{array}{r}\text { PPV } \\
(\%) \\
\end{array}$ & $\begin{array}{r}\text { NPV } \\
(\%) \\
\end{array}$ & $\begin{array}{c}\text { OR } \\
(95 \% \mathrm{CI}) \\
\end{array}$ & $P$ \\
\hline \multicolumn{9}{|c|}{ Olfactory deficit } \\
\hline (a) Yes & $\begin{array}{c}37 \\
(77.1 \%)\end{array}$ & $\begin{array}{c}11 \\
(22.9 \%)\end{array}$ & \multirow[t]{2}{*}{72.6} & \multirow[t]{2}{*}{81.0} & \multirow[t]{2}{*}{77.1} & \multirow[t]{2}{*}{77.1} & \multirow[t]{2}{*}{$\begin{array}{c}11.29 \\
(4.59-27.76)\end{array}$} & \multirow[t]{2}{*}{$<0.0001$} \\
\hline (b) No & $\begin{array}{c}14 \\
(23.0 \%)\end{array}$ & $\begin{array}{c}47 \\
(77.0 \%)\end{array}$ & & & & & & \\
\hline \multicolumn{9}{|c|}{$\begin{array}{l}\text { Pupillary hypersensitivity } \\
\text { response }\end{array}$} \\
\hline (a) Yes & $\begin{array}{c}44 \\
(77.2 \%)\end{array}$ & $\begin{array}{c}13 \\
(22.8 \%)\end{array}$ & \multirow[t]{2}{*}{86.3} & \multirow[t]{2}{*}{77.6} & \multirow[t]{2}{*}{77.2} & \multirow[t]{2}{*}{86.5} & \multirow[t]{2}{*}{$\begin{array}{c}21.76 \\
(7.94-59.65)\end{array}$} & \multirow[t]{2}{*}{$<0.0001$} \\
\hline (b) No & $\begin{array}{c}7 \\
(13.5 \%)\end{array}$ & $\begin{array}{c}45 \\
(86.5 \%)\end{array}$ & & & & & & \\
\hline \multicolumn{9}{|c|}{$\begin{array}{l}\text { Olfactory deficit and } \\
\text { APOE } \varepsilon 4^{*}\end{array}$} \\
\hline (a) Yes & $\begin{array}{c}13 \\
(92.9 \%)\end{array}$ & $\begin{array}{c}1 \\
(7.1 \%)\end{array}$ & \multirow[t]{2}{*}{26.0} & \multirow[t]{2}{*}{98.3} & \multirow[t]{2}{*}{92.9} & \multirow[t]{2}{*}{60.2} & \multirow{2}{*}{$\begin{array}{c}19.68 \\
(2.47-156.85)\end{array}$} & \multirow[t]{2}{*}{0.01} \\
\hline (b) No & $\begin{array}{c}37 \\
(39.8 \%)\end{array}$ & $\begin{array}{c}56 \\
(60.2 \%)\end{array}$ & & & & & & \\
\hline \multicolumn{9}{|c|}{$\begin{array}{l}\text { Olfactory deficit and } \\
\text { low BDNF plasma level }\end{array}$} \\
\hline (a) Yes & $\begin{array}{c}22 \\
(84.6 \%)\end{array}$ & $\begin{array}{c}4 \\
(15.4 \%)\end{array}$ & \multirow[t]{2}{*}{43.1} & \multirow[t]{2}{*}{93.1} & \multirow[t]{2}{*}{84.6} & \multirow[t]{2}{*}{65.1} & \multirow[t]{2}{*}{$\begin{array}{c}10.24 \\
(3.22-32.57)\end{array}$} & \multirow[t]{2}{*}{$<0.0001$} \\
\hline (b) No & $\begin{array}{c}29 \\
(34.9 \%)\end{array}$ & $\begin{array}{c}54 \\
(65.1 \%)\end{array}$ & & & & & & \\
\hline \multicolumn{9}{|c|}{$\begin{array}{l}\text { Pupillary hypersensitivity } \\
\text { response and APOE } \varepsilon 4^{*}\end{array}$} \\
\hline (a) Yes & $\begin{array}{c}13 \\
(76.5 \%)\end{array}$ & $\begin{array}{c}4 \\
(23.5 \%)\end{array}$ & \multirow[t]{2}{*}{26.0} & \multirow[t]{2}{*}{92.9} & \multirow[t]{2}{*}{76.5} & \multirow[t]{2}{*}{58.9} & \multirow[t]{2}{*}{$\begin{array}{c}4.66 \\
(1.41-15.41)\end{array}$} & 0.016 \\
\hline (b) No & $\begin{array}{c}37 \\
(41.1 \%)\end{array}$ & $\begin{array}{c}53 \\
(58.9 \%)\end{array}$ & & & & & & \\
\hline $\begin{array}{l}\text { Pupillary } \\
\text { response a } \\
\text { plasma lev }\end{array}$ & & & & & & & & \\
\hline (a) Yes & $\begin{array}{c}20 \\
(79.9 \%)\end{array}$ & $\begin{array}{c}6 \\
(23.1 \%)\end{array}$ & 39.2 & 89.7 & 76.9 & 62.7 & $\begin{array}{c}5.59 \\
(2.03-15.43)\end{array}$ & 0.001 \\
\hline (b) No & $\begin{array}{c}31 \\
(37.3 \%)\end{array}$ & $\begin{array}{c}52 \\
(62.7 \%)\end{array}$ & & & & & & \\
\hline $\begin{array}{l}\text { Olfactory } \\
\text { hypersens }\end{array}$ & & & & & & & & \\
\hline (a) Yes & $\begin{array}{c}33 \\
(86.8 \%)\end{array}$ & $\begin{array}{c}5 \\
(13.2 \%)\end{array}$ & 64.7 & 91.4 & 86.8 & 74.7 & $\begin{array}{c}19.43 \\
(6.59-5734)\end{array}$ & $<0.0001$ \\
\hline (b) No & $\begin{array}{c}18 \\
(25.4 \%)\end{array}$ & $\begin{array}{c}53 \\
(74.6 \%)\end{array}$ & & & & & & \\
\hline
\end{tabular}

Note. ${ }^{*}$ APOE $\varepsilon 2 / \varepsilon 4$ genotype is not included.

Combination of olfactory nerve deficit and pupillary hypersensitivity response generated good values of specificity/Sp $91 \%$, positive predictive value/PPV $87 \%$, and negative predictive value/NPV $75 \%$ when differentiating aMCI from those with normal cognition. In conjunction with clinical markers, low BDNF plasma level and presence of $\varepsilon 4+$ substantially increased specificity and PPV (Table 3 ).

In the end of the study, we replicated the test on different group (30 subjects) and the results were almost identical.
Combination of olfactory deficit and pupillary hypersensitivity response in differentiating aMCI from normal cognitive function yielded Sv 70\%, Sp 95\%, PPV 88\%, and NPV 86\%.

\section{Discussion}

The majority of the subjects in this study came from low educational background. This finding is similar to other study of the elderly population in Indonesia [44]. This may also 
explain the high prevalence of aMCI (43\%) found in our study. The prevalence is higher compared to a study by Luck et al. that stated that the prevalence of aMCI was $17 \%$ among elderly aged $>65$ years old [54].

Four of five subjects with $\varepsilon 4+/+$ also showed multipledomain aMCI. Blom et al. reported that seven of eight aMCI patients with $\varepsilon 4+/+$ genotypes eventually progressed to dementia [55]. We found significant difference in pupillary response and olfactory scores for each type of MCI. Pupil dilatation response in those with multiple-domain aMCI was higher in comparison with normal cognition $(P<0.0001)$. Arai et al. stated that elderly with $\mathrm{AD}$ demonstrated pupil dilatation up to $43 \%$ when compared to $15.6 \%$ in those with normal cognition [56]. In this study, multiple-domain aMCI subjects scored the lowest olfactory score compared to those with single-domain aMCI and normal cognition (Table 3). It has been widely known that multiple-domain aMCI has the worst outcome and a predisposing factor toward dementia [57].

Higuchi et al. reported a significant relationship between $\varepsilon 4+$ and pupil hypersensitivity response [21]. In a study by Wang et al., they demonstrated the difference between subjects with and without $\varepsilon 4$ allele in identifying the odors [9]. In our study, subjects with $\varepsilon 4$ homozygote significantly demonstrated the lowest olfactory scores and highest pupillary hypersensitivity response.

We did not find a significant relationship between APOE and aMCI. Due to the multifactorial nature, APOE solely could not be held responsible for the disease. Despite the fact that APOE $\varepsilon 4$ genotype is a risk factor that accelerates degenerative process in the brain $(\mathrm{AD}), \varepsilon 4$ carrier status alone could not be accountable for cognitive decline or dementia [58].

The peak dilatation response to $0.01 \%$ tropicamide was about $30 \mathrm{~min}$ in this study which was similar to other reports $[17,25,56,59,60]$. Pupillary response to tropicamide was previously studied to expose degenerative process in Edinger Westphal nucleus. This area demonstrated degeneration in early stage of $\mathrm{AD}$ [61]. Pupillary response is an objective test that does not require neuropsychological examination/ interview. This can be beneficial in special cases where patients are not able to participate in neuropsychological test. However, this test is not suitable for those with eye disorders such as history of cataract surgery and in diabetes mellitus patients (in whom autonomy nervous system has been compromised).

In our study, the cut-off point for pupil dilatation is $>22 \%$ for differentiating elderly with aMCI. There are various cutoff points in other publications that may due be to different patients criteria, different age group, and concentration of tropicamide being administered. Scinto et al. reported a cutoff point of $13 \%$ in 30 minutes to differentiate dementia and normal cognition in the elderly using $0.01 \%$ tropicamide [17]. Another report by Iijima et al. used a cut-off point of $14.5 \%$ in 60 minutes using less concentrated tropicamide $(0.005 \%)$ [20].

In our study, we established the cut-off point $<7$ for olfactory score to diagnose aMCI in elderly. Eibenstein et al. set a higher cut-off point $\geq 10$ (out of 12) to differentiate elderly with normal cognition and aMCI and stated that scores $\leq 6$ were anosmic [7]. A study by Tabert et al. using 10 different odors set a cut-off point $\leq 7$ in differentiating DA with aMCI [8]. Olfactory test is not similar with cognitive assessment because the former is not influenced by educational level nor depression; hence, it is suitable to use in elderly patients with low level of education and depression [4].

Lower level of BDNF was observed in aMCI group than elderly with normal cognition $(P=0.04)$. This is supported by a study by Lee et al., where they observed low level of BDNF in MCI and dementia patients [40].

High LDL level is undoubtedly a risk factor for vascular disease but its connection with cognitive dysfunction has not yet been established. Yasuno et al. declared no relationship between level of LDL, triglycerides, and total cholesterol with cognitive scores [62]. Another study by Elias et al. also showed no relationship between aMCI and cholesterol, specifically between total cholesterol and memory domain [63]. Reitz et al. stated that plasma lipid levels in the elderly are not associated with the risk of MCI [64]. The relationship between HDL and cognitive function is still inconclusive. Van Exel et al. stated that low HDL level was related to low MMSE scores and these low scores of MMSE did not result from the atherosclerosis process [65]. In contrary, Gillum and Obisesan did not find any significant relationship between HDL level and cognitive function [66].

There was no significant relationship between systolic and diastolic hypertension with aMCI in our study. The issue of hypertension and $\mathrm{aMCI}$ and dementia remains controversial. Vascular disease is a risk factor for developing MCI in some studies $[67,68]$. Farmer et al. stated that there was no relationship between hypertension and cognitive dysfunction [69]. In another research conducted in Jakarta involving 1001 elderly patients with mean age $68 \pm 7$ years old, there was no relationship between recall memory and total MMSE scores with hypertension [70]. A different finding is shown by Reitz et al. using 918 subjects, followed for mean of 4.7 years where they found hypertension as a risk factor for nonamnestic MCI (naMCI) not for aMCI [71].

In this study, 13 of 14 subjects with olfactory deficit and $\varepsilon 4+$ genotypes presented with aMCI $(\mathrm{OR}=20)$. Graves et al. stated that subjects with olfactory deficit and $\varepsilon 4+$ genotype were 4.9 times likely to suffer from cognitive decline compared to those without olfactory deficit and $\varepsilon 4-[10]$. We also observed subjects with pupillary hypersensitivity and having $\varepsilon 4+$ genotype was 4.7 times likely to have aMCI. Hence, presence of $\varepsilon 4+$ genotype may substantially increase specificity and positive predictive value toward aMCI. In addition, our study showed that 22 out of 26 patients with olfactory deficit and low BDNF plasma level had aMCI (OR = $10)$.

Based on the findings in our study, biological markers, such as APOE and BDNF, when used in conjunction with clinical markers of pupillary response or olfactory test can increase positive predictive value (PPV) toward aMCI diagnosis. Our findings supported the statement by Lautenschlager et al. that combination of biological and clinical markers is essential to increase PPV in MCI diagnosis [72]. 
Multivariate analysis in our study revealed that olfactory deficit and pupillary response were related significantly to aMCI. We also found that combination of olfactory test and pupillary response to tropicamide was the best model when considering Sp and PPV (Sv 64,7\%, Sp 91,4\%, and PPV 86,8\%) in comparison to the other combination. We do acknowledge the limitation of our study that we did not perform analysis for combinations of three or more variables due to sample size. To our knowledge, this is the first research combining the two variables at one time. Taking into consideration that the two markers can aid the psychometric evaluation for diagnosis (not for screening purpose), hence, higher specificity is more important than sensitivity.

When we replicated the test on different group (30 subjects), the results for diagnostic values of olfactory deficit and pupillary response were almost identical. The combination of two clinical markers can increase the specificity up to $95 \%$ and PPV up to $88 \%$. This shows that the diagnostic values of pupillary response to tropicamide and olfactory deficit in diagnosing aMCI were consistent.

We share optimism that, in the future, combination of these two clinical markers (olfactory test and pupillary response to tropicamide) can be widely implemented together with cognitive assessment. Hence, clinicians can perform early diagnosis of the degenerative process in the brain using various alternatives and institute proper treatment for a better quality of life in the elderly.

\section{Conflict of Interests}

The authors do not have any direct financial relation with the trademarks mentioned in the paper that might lead to a conflict of interests for any of the authors. The authors declare no potential conflict of interests.

\section{References}

[1] R. C. Petersen, G. E. Smith, S. C. Waring, R. J. Ivnik, E. G. Tangalos, and E. Kokmen, "Mild cognitive impairment: clinical characterization and outcome," Archives of Neurology, vol. 56, no. 3, pp. 303-308, 1999.

[2] K. Schmidtke and S. Hermeneit, "High rate of conversion to Alzheimer's disease in a cohort of amnestic MCI patients," International Psychogeriatrics, vol. 20, no. 1, pp. 96-108, 2008.

[3] R. C. Petersen, J. E. Parisi, D. W. Dickson et al., "Neuropathologic features of amnestic mild cognitive impairment," Archives of Neurology, vol. 63, no. 5, pp. 665-672, 2006.

[4] R. J. McCaffrey, K. Duff, and G. S. Solomon, "Olfactory dysfunction discriminates probable Alzheimer's dementia from major depression: a cross-validation and extension," Journal of Neuropsychiatry and Clinical Neurosciences, vol. 12, no. 1, pp. 2933, 2000.

[5] M. Serby, P. Larson, and D. Kalkstein, "The nature and course of olfactory deficits in Alzheimer's disease," The American Journal of Psychiatry, vol. 148, no. 3, pp. 357-360, 1991.

[6] R. L. Doty, A. Marcus, and W. W. Lee, "Development of the 12 item cross cultural smell identification test (CC-SIT)," Laryngoscope, vol. 106, no. 3, pp. 353-356, 1996.
[7] A. Eibenstein, A. B. Fioretti, M. N. Simaskou et al., "Olfactory screening test in mild cognitive impairment," Neurological Sciences, vol. 26, no. 3, pp. 156-160, 2005.

[8] M. H. Tabert, X. Liu, R. L. Doty et al., "A 10-item smell identification scale related to risk for Alzheimer's disease," Annals of Neurology, vol. 58, no. 1, pp. 155-160, 2005.

[9] Q.-S. Wang, L. Tian, Y.-L. Huang, S. Qin, L.-Q. He, and J.-N. Zhou, "Olfactory identification and apolipoprotein E $\varepsilon 4$ allele in mild cognitive impairment," Brain Research, vol. 951, no. 1, pp. 77-81, 2002.

[10] A. B. Graves, J. D. Bowen, L. Rajaram et al., "Impaired olfaction as a marker for cognitive decline: interaction with apolipoprotein E $\varepsilon 4$," Neurology, vol. 53, no. 7, pp. 1480-1487, 1999.

[11] D. P. Devanand, K. S. Michaels-Marston, X. Liu et al., "Olfactory deficits in patients with mild cognitive impairment predict Alzheimer's disease at follow-up," The American Journal of Psychiatry, vol. 157, no. 9, pp. 1399-1405, 2000.

[12] C. Murphy, T. L. Jernigan, and C. Fennema-Notestine, "Left hippocampal volume loss in Alzheimer's disease is reflected in performance on odor identification: a structural MRI study," Journal of the International Neuropsychological Society, vol. 9, no. 3, pp. 459-471, 2003.

[13] M. D. Warner, C. A. Peabody, J. J. Flattery, and J. R. Tinklenberg, "Olfactory deficits and Alzheimer's disease," Biological Psychiatry, vol. 21, no. 1, pp. 116-118, 1986.

[14] E. Koss, “Olfactory dysfunction in Alzheimer's disease," Developmental Neuropsychology, vol. 2, no. 2, pp. 89-99, 1986.

[15] R. L. Doty, P. F. Reyes, and T. Gregor, "Presence of both odor identification and detection deficits in Alzheimer's disease," Brain Research Bulletin, vol. 18, no. 5, pp. 597-600, 1987.

[16] E. Koss, J. M. Weiffenbach, J. V. Haxby, and R. P. Friedland, "Olfactory detection and identification performance are dissociated in early Alzheimer's disease," Neurology, vol. 38, no. 8, pp. 1228-1232, 1988.

[17] L. F. M. Scinto, K. R. Daffner, D. Dressler et al., "A potential noninvasive neurobiological test for Alzheimer's disease," Science, vol. 266, no. 5187, pp. 1051-1054, 1994.

[18] J. Grünberger, L. Linzmayer, H. Walter et al., "Receptor test (pupillary dilatation after application of $0.01 \%$ tropicamide solution) and determination of central nervous activation (Fourier analysis of pupillary oscillations) in patients with Alzheimer's disease," Neuropsychobiology, vol. 40, no. 1, pp. 40-46, 1999.

[19] J. Fourie, Age dependent pupillary and cognitive responses to cholinergic drugs as a model for identification of future biological markers for Alzheimer disease [Ph.D. thesis], University of Toronto, Toronto, Canada, 1999.

[20] A. Iijima, M. Haida, N. Ishikawa, A. Ueno, H. Minamitani, and Y. Shinohara, "Re-evaluation of tropicamide in the pupillary response test for Alzheimer's disease," Neurobiology of Aging, vol. 24, no. 6, pp. 789-796, 2003.

[21] S. Higuchi, S. Matsushita, Y. Hasegawa, T. Muramatsu, H. Arai, and M. Hayashida, "Apolipoprotein E $\varepsilon 4$ allele and pupillary response to tropicamide," The American Journal of Psychiatry, vol. 154, no. 5, pp. 694-696, 1997.

[22] E. Gómez-Tortosa, A. del Barrio, and I. Jiménez-Alfaro, "Pupil response to tropicamide in Alzheimer's disease and other neurodegenerative disorders," Acta Neurologica Scandinavica, vol. 94, no. 2, pp. 104-109, 1996.

[23] S. Higuchi, S. Matsushita, Y. Hasegawa, T. Muramatsu, and H. Arai, "Pupillary response to tropicamide in Japanese patients with alcoholic dementia, Alzheimer's disease, and vascular 
dementia," Experimental Neurology, vol. 144, no. 1, pp. 199-201, 1997.

[24] Y. Imamura, H. Kojima, and K. Haraoka, "Pupil dilatation response to the acethylcholine receptor antagonist tropicamide in normal aged and senile dementia subjects," Neurobiology of Aging, vol. 17, no. 4, supplement 1, p. S165, 1996.

[25] J. Kálmán, A. Kanka, E. Maglóczky, A. Szóke, T. Járdánházy, and Z. Janka, "Increased mydriatic response to tropicamide is a sign of cholinergic hypersensitivity but not specific to late-onset sporadic type of Alzheimer's dementia," Biological Psychiatry, vol. 41, no. 8, pp. 909-911, 1997.

[26] S. Matsushita, H. Arai, Y. Hasegawa et al., "Apolipoprotein Ee4 allele and pupillary response to tropicamide in Alzheimer's disease and cognitively normal subjects," Neurobiology of Aging, vol. 17, no. 4, supplement 1, p. S164, 1996.

[27] A. M. Titus, P. Revest, and P. Shortland, The Nervous System, Basic Science and Clinical Conditions, Elseiver, New York, NY, USA, 2007.

[28] N. Ertekin-Taner, "Genetics of Alzheimer's disease: a centennial review," Neurologic Clinics, vol. 25, no. 3, pp. 611-667, 2007.

[29] T. Polvikoski, R. Sulkava, M. Haltia et al., "Apolipoprotein E, dementia, and cortical deposition of $\beta$-amyloid protein," The New England Journal of Medicine, vol. 333, no. 19, pp. 1242-1247, 1995.

[30] R. C. Petersen, G. E. Smith, R. J. Ivnik et al., “The APOE $\varepsilon 4$ status as a predictor of the developmental of Alzheimer's disease in memory impaired individuals," The Journal of the American Medical Association, vol. 273, no. 16, pp. 1274-1278, 1995.

[31] B. J. Small, C. B. Rosnick, L. Fratiglioni, and L. Bäckman, "APOE $\varepsilon 4$ and cognitive performance: a metaanalysis," Psychology and Aging, vol. 19, no. 4, pp. 592-600, 2004.

[32] A. E. van der Vlies, Y. A. L. Pijnenburg, T. Koene et al., "Cognitive impairment in Alzheimer's disease is modified by APOE genotype," Dementia and Geriatric Cognitive Disorders, vol. 24, no. 2, pp. 98-103, 2007.

[33] I. H. G. B. Ramakers, P. J. Visser, P. Aalten et al., "The association between APOE genotype and memory dysfunction in subjects with mild cognitive impairment is related to age and Alzheimer pathology," Dementia and Geriatric Cognitive Disorders, vol. 26, no. 2, pp. 101-108, 2008.

[34] P. A. Boyle, A. S. Buchman, R. S. Wilson, J. F. Kelly, and D. A. Bennett, "The APOE $\varepsilon 4$ allele is associated with incident mild cognitive impairment among community-dwelling older persons," Neuroepidemiology, vol. 34, no. 1, pp. 43-49, 2010.

[35] C. Cunha, R. Brambilla, and K. L. Thomas, "A simple role for BDNF in learning and memory?" Frontiers in Molecular Neuroscience, vol. 3, pp. 1-14, 2010.

[36] C. Laske, E. Stransky, T. Leyhe et al., "BDNF serum and CSF concentrations in Alzheimer's disease, normal pressure hydrocephalus and healthy controls," Journal of Psychiatric Research, vol. 41, no. 5, pp. 387-394, 2007.

[37] W. Pan, W. A. Banks, M. B. Fasold, J. Blunth, and A. J. Katin, "Transport of BDNF across the BBB," Neuropharmacology, vol. 37, no. 12, pp. 1553-1561, 2006.

[38] G. Dogliotti, E. Galliera, F. Licastro, and M. M. Corsi, "Agerelated changes in plasma levels of BDNF in Down syndrome patients," Immunity and Ageing, vol. 7, article 2, 2010.

[39] H. Yu, Z. Zhang, Y. Shi et al., "Association study of the decreased serum BDNF concentrations in amnestic mild cognitive impairment and the Val66Met polymorphism in Chinese han," Journal of Clinical Psychiatry, vol. 69, no. 7, pp. 1104-1111, 2008.
[40] J. G. Lee, B. S. Shin, Y. S. You et al., "Decreased serum brainderived neurotrophic factor levels in elderly Korean with dementia," Psychiatry Investigation, vol. 6, no. 4, pp. 299-305, 2009.

[41] K. S. Hwang, K. Gylys, K. Taylor et al., "Plasma BDNF associations with cortical thickness in normal controls and mild cognitive impairment," Alzheimer's \& Dementia, vol. 7, no. 4, supplement, p. S319, 2011.

[42] O. von Bohlen and Halbach, "Involvement of BDNF in agedependent alterations in the hippocampus," Frontiers in Aging Neuroscience, vol. 2, pp. 1-11, 2010.

[43] O. Suchowersky, S. Reich, J. Perlmutter, T. Zesiewicz, G. Gronseth, and W. J. Weiner, "Practice parameter: diagnosis and prognosis of new onset Parkinson disease (an evidence-based review): report of the Quality Standards Subcommittee of the American Academy of Neurology," Neurology, vol. 66, no. 7, pp. 968-975, 2006.

[44] Y. S. Handajani, Disability measurement index and prediction of the life quality of the elderly in DKI Jakarta [Ph.D. thesis], University of Indonesia, Depok, Indonesia, 2006.

[45] J. A. Yesavage, T. L. Brink, T. L. Rose et al., "Development and validation of a geriatric depression screening scale: a preliminary report," Journal of Psychiatric Research, vol. 17, no. 1, pp. 37-49, 1983.

[46] American Diabetes Association, "Standard of medical care in diabetes 2012," Diabetes Care, vol. 35, pp. S11-S63, 2012.

[47] Asian-Pacific Type 2 Diabetes Policy Group, Type 2 Diabetes: Practical Targets and Treatments, Melbourne, Australia, 3rd edition, 2002.

[48] K. A. Welsh, N. Butters, R. C. Mohs et al., "The Consortium to Establish a Registry for Alzheimer's Disease (CERAD). Part V. A normative study of the neuropsychological battery," Neurology, vol. 44, no. 4, pp. 609-614, 1994.

[49] B. Winblad, K. Palmer, M. Kivipelto et al., "Mild cognitive impairment-beyond controversies, towards a consensus: report of the International Working Group on Mild Cognitive Impairment," Journal of Internal Medicine, vol. 256, no. 3, pp. 240-246, 2004.

[50] J. J. Luhur, Mirsha, Y. S. Handajani, and Y. Turana, "Determination of familiar odors for standard examination of olfactory function of the elderly in Jakarta," Neurona, vol. 29, pp. 7-13, 2012.

[51] M. K. Yoon, G. Schmidt, T. Lietman, and S. D. McLeod, "Interexaminer and intraexaminer reliability of pupil diameter measurement using the colvard pupillometer," Investigative Ophthalmology and Visual Science, vol. 44, 2003.

[52] S. Bootsma, N. Tahzib, F. Eggink, J. de Brabander, and R. M. M. A. Nuijts, "Comparison of two pupillometers in determining pupil size for refractive surgery," Acta Ophthalmologica Scandinavica, vol. 85, no. 3, pp. 324-328, 2007.

[53] E. Granholm, S. Morris, D. Galasko, C. Shults, E. Rogers, and B. Vukov, "Tropicamide effects on pupil size and pupillary light reflexes in Alzheimer's and Parkinson's disease," International Journal of Psychophysiology, vol. 47, no. 2, pp. 95-115, 2003.

[54] T. Luck, S. G. Riedel-Heller, H. Kaduszkiewicz et al., "Mild cognitive impairment in general practice: age-specific prevalence and correlate results from the German study on ageing, cognition and dementia in primary care patients (AgeCoDe)," Dementia and Geriatric Cognitive Disorders, vol. 24, no. 4, pp. 307-316, 2007.

[55] E. S. Blom, V. Giedraitis, H. Zetterberg et al., "Rapid progression from mild cognitive impairment to alzheimer's disease in 
subjects with elevated levels of tau in cerebrospinal fluid and the Apoe $\varepsilon 4 / \varepsilon 4$ genotype," Dementia and Geriatric Cognitive Disorders, vol. 27, no. 5, pp. 458-464, 2009.

[56] H. Arai, M. Terajima, T. Nakagawa, S. Higuchi, H. Mochizuki, and H. Sasaki, "Pupil dilatation assay by tropicamide is modulated by apolipoprotein e $\in 4$ allele dosage in Alzheimer's disease," NeuroReport, vol. 7, no. 4, pp. 918-920, 1996.

[57] R. C. Petersen, J. C. Stevens, M. Ganguli, E. G. Tangalos, J. L. Cummings, and S. T. DeKosky, "Practice parameter: early detection of dementia: mild cognitive impairment (an evidencebased review). Report of the Quality Standards Subcommittee of the American Academy of Neurology," Neurology, vol. 56, no. 9, pp. 1133-1142, 2001.

[58] D. P. Devanand, G. H. Pelton, D. Zamora et al., "Predictive utility of apolipoprotein E genotype for Alzheimer disease in outpatients with mild cognitive impairment," Archives of Neurology, vol. 62, no. 6, pp. 975-980, 2005.

[59] M. Fridh, U. Havelius, G. Elofsson, and B. Hindfelt, "The pupillary response to tropicamide in Alzheimer's disease," Acta Ophthalmologica Scandinavica, vol. 74, no. 3, pp. 276-279, 1996.

[60] A. Kurz, R. Marquard, S. Fremke, and K. P. Leipert, "Pupil dilation response to tropicamide: a biological test for Alzheimer's disease?" Pharmacopsychiatry, vol. 30, no. 1, pp. 12-15, 1997.

[61] L. F. M. Scinto, M. Frosch, C. K. Wu, K. R. Daffner, N. Gedi, and C. Geula, "Selective cell loss in Edinger-Westphal in asymptomatic elders and Alzheimer's patients," Neurobiology of Aging, vol. 22, no. 5, pp. 729-736, 2001.

[62] F. Yasuno, S. Tanimukai, M. Sasaki et al., "Association between cognitive function and plasma lipids of the elderly after controlling for apolipoprotein E genotype," American Journal of Geriatric Psychiatry, vol. 20, pp. 574-583, 2012.

[63] P. K. Elias, M. F. Elias, R. B. D’Agostino, L. M. Sullivan, and P. A. Wolf, "Serum cholesterol and cognitive performance in the Framingham Heart Study," Psychosomatic Medicine, vol. 67, no. 1, pp. 24-30, 2005.

[64] C. Reitz, M.-X. Tang, J. Manly, N. Schupf, R. Mayeux, and J. A. Luchsinger, "Plasma lipid levels in the elderly are not associated with the risk of mild cognitive impairment," Dementia and Geriatric Cognitive Disorders, vol. 25, no. 3, pp. 232-237, 2008.

[65] E. van Exel, A. J. M. de Craen, J. Gussekloo et al., "Association between high-density lipoprotein and cognitive impairment in the oldest old," Annals of Neurology, vol. 51, no. 6, pp. 716-721, 2002.

[66] R. F. Gillum and T. O. Obisesan, "High-density lipoprotein cholesterol, cognitive function and mortality in a U.S. national cohort," Lipids in Health and Disease, vol. 10, article 26, 2011.

[67] O. L. Lopez, W. J. Jagust, C. Dulberg et al., "Risk factors for mild cognitive impairment in the cardiovascular health study cognition study," Archives of Neurology, vol. 60, no. 10, pp. 1394-1399, 2003.

[68] S. Tervo, M. Kivipelto, T. Hänninen et al., "Incidence and risk factors for mild cognitive impairment: a population-based three-year follow-up study of cognitively healthy elderly subjects," Dementia and Geriatric Cognitive Disorders, vol. 17, no. 3 , pp. 196-203, 2004.

[69] M. E. Farmer, S. J. Kittner, R. D. Abbott, M. M. Wolz, P. A. Wolf, and L. R. White, "Longitudinally measured blood pressure, antihypertensive medication use, and cognitive performance: The Framingham Study," Journal of Clinical Epidemiology, vol. 43, no. 5, pp. 475-480, 1990.

[70] Y. Turana and Y. S. Handayani, "Relationship between vascular risk factors and physical exercise with cognitive function of the elderly in Jakarta," in Proceedings of the INASH Scientific Meeting, February 2010.

[71] C. Reitz, M.-X. Tang, J. Manly, R. Mayeux, and J. A. Luchsinger, "Hypertension and the risk of mild cognitive impairment," Archives of Neurology, vol. 64, no. 12, pp. 1734-1740, 2007.

[72] N. T. Lautenschlager, L. Flicker, S. Vasikaran, P. Leedman, and O. P. Almeida, "Subjective memory complaints with and without objective memory impairment: relationship with risk factors for dementia," American Journal of Geriatric Psychiatry, vol. 13, no. 8, pp. 731-734, 2005. 


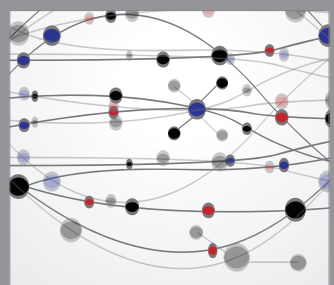

The Scientific World Journal
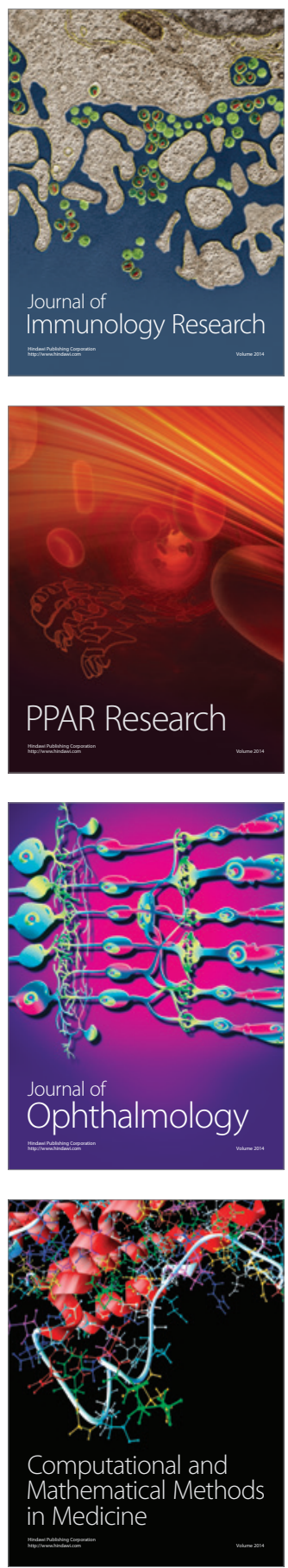

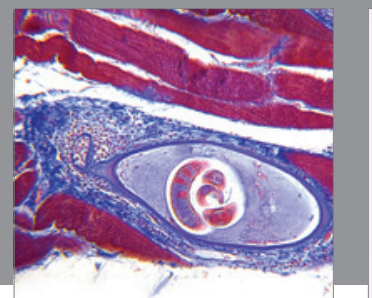

Gastroenterology

Research and Practice
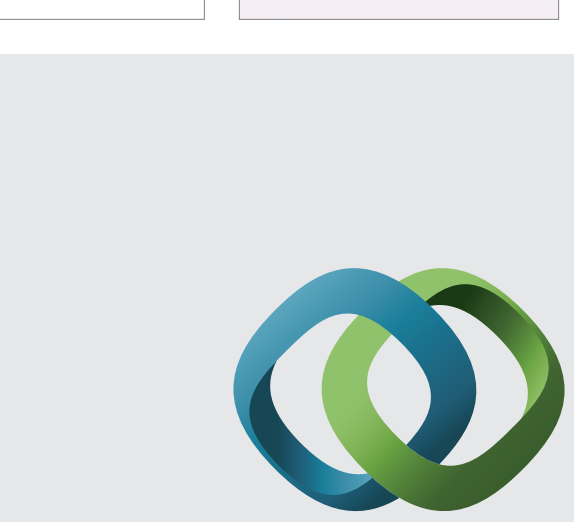

\section{Hindawi}

Submit your manuscripts at

http://www.hindawi.com
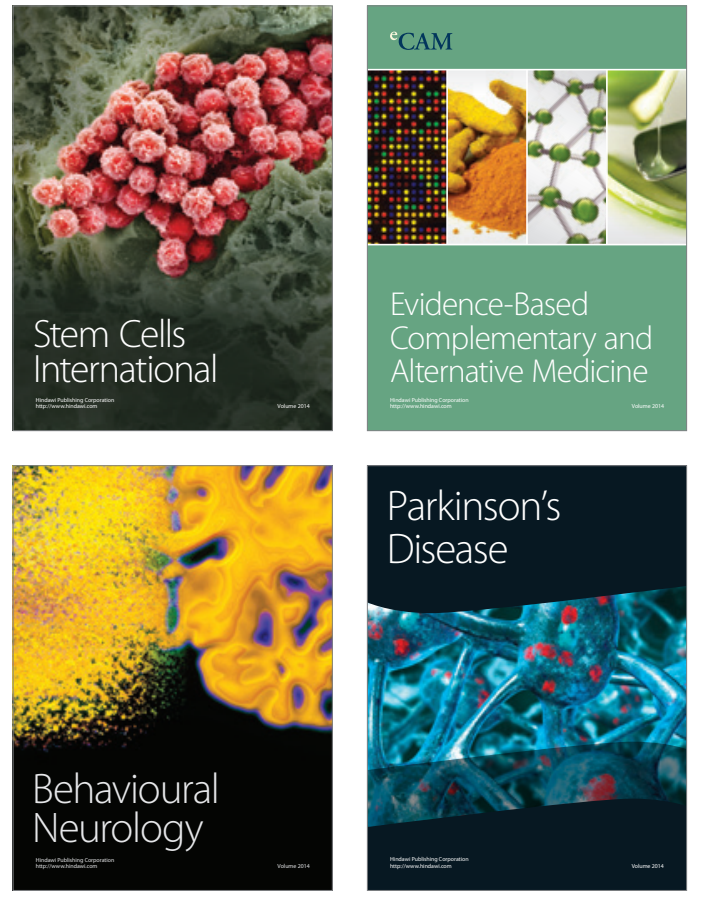
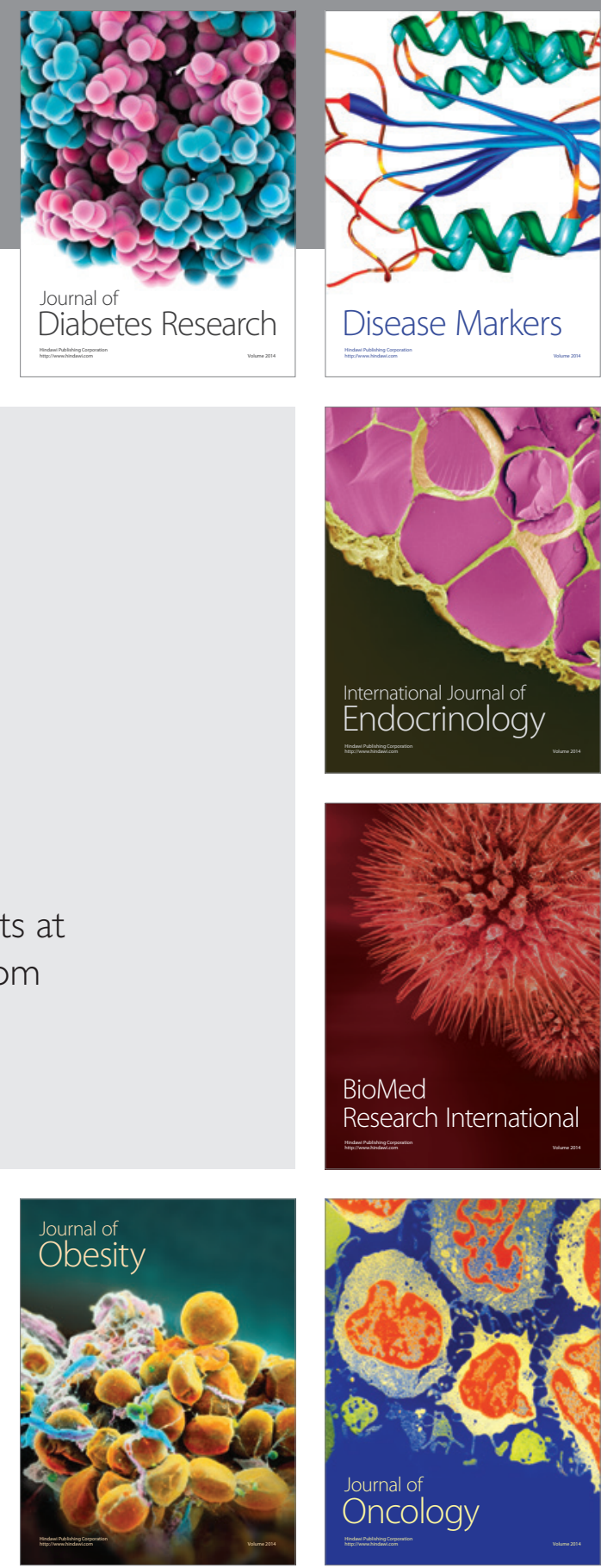

Disease Markers
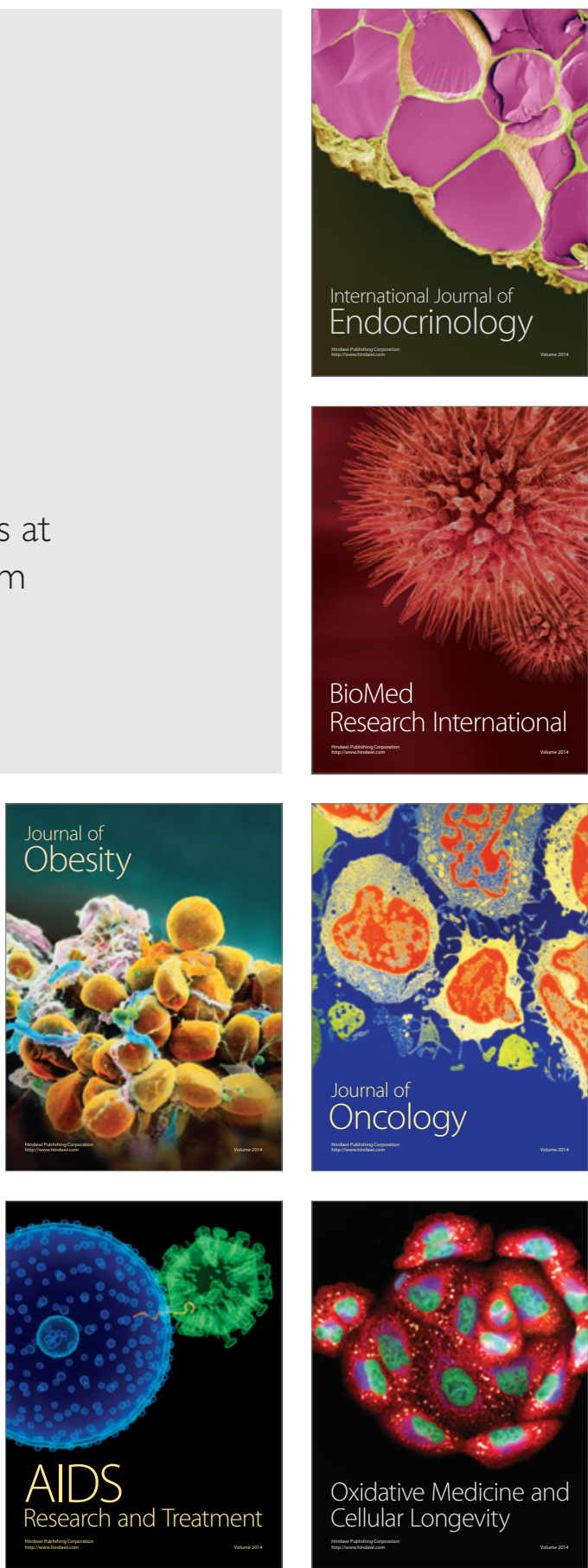